\title{
Drought Index Mapping in Java Island Using Sentinel-3 SLSTR
}

\author{
Wijayanti, R. F., ${ }^{1,2}$ Jaelani, L. M., ${ }^{*}$ Handayani, H. H. ${ }^{1}$ and Chu, H. J. ${ }^{2}$ \\ ${ }^{1}$ Department of Geomatics Engineering, Institut Teknologi Sepuluh Nopember (ITS), Indonesia \\ E-mai: regitafw@gmail.com,lmjaelani@geodesy.its.ac.id, hapsari@geodesy.its.ac.id \\ ${ }^{2}$ Department of Geomatics, National Cheng-Kung University, Taiwan \\ E-mail: honejaychu@geomatics.ncku.edu \\ ${ }^{*}$ Correspondence Author
}

DOI: https://doi.org/10.52939/ijg.v17i4.1959

\begin{abstract}
As the most populous island globally, Java Island has various vulnerabilities to disasters ranging from geological to hydro-meteorological. One of the most common hydro-meteorological disasters is the drought that occurs every year in the dry season. This disaster causes crop failure, land and forest fires, and clean water shortages. In this study, the Sea and Land Surface Temperature Radiometer (SLSTR) instrument onboard the Sentinel-3 platform was used to map drought using the Vegetation Temperature Condition Index (VTCI) algorithm based on the scattering space technique of Land Surface Temperature (LST) and Normalized Different Vegetation Index (NDVI). During 2018, the highest and lowest LST occurred on September 28 ( $\left.309^{\circ} \mathrm{K}\right)$, and February 1 ( $\left.278^{\circ} \mathrm{K}\right)$; the highest and lowest NDVI occurred on July $1(0.466)$ and November 13 (0.221). In comparison, the driest conditions indicated the lowest VTCI (0.162) on July 17 and the wettest on August 28 (0.508). The driest and wettest situation co-occurred: at the end of the dry session and the rainy session, it shows that the rain greatly contributes to high VTCI. A regular drought mapping needs to be performed as an effort to disaster risk reduction. Drought maps are then used as a spatial recommendation in reforestation intervention to reduce drought in the future.
\end{abstract}

\section{Introduction}

Drought is a continuous period of water availability under normal. It is a recurring and worldwide phenomenon, with spatial and temporal characteristics that vary significantly from region to region (Tallaksen and van Lanenm 2004 and van Loon, 2015). One of the things that affect the seasons in Indonesia is the El Nino event. El Nino is a global climate change phenomenon caused by the warming of the sea surface temperature of the eastern Pacific, which brings warm air from the continent of Australia to the continent of Asia, which causes the air in Indonesia to become dry. As the most populous island globally, Java Island faces a high vulnerability to disasters, especially drought. This island is located in the southern part of Indonesia, bordered by the Indian Ocean on the south and the Java Sea on the north; thus, it was directly affected by the El Nino incident (Safitri, 2015).

According to the Indonesian Disaster Data and Information (DIBI) from the National Disaster Management Agency (BNPB) for the last two centuries, which was recorded from 1815 to March 2015 , as many as $79.4 \%$ of natural disasters in
Indonesia were categorized as hydro-meteorological disasters, others: floods, landslides, drought, forest, and land fires, and tornadoes (Murdiyarso and Adiningsih, 2007). The final impact of disasters, especially drought, is the culmination of the socioeconomic effects on people and livelihoods (Adede et al., 2019). Disaster-prone mapping, early warning, monitoring, and disaster mitigation are among the primary needs in the disaster management cycle to reduce socio-economic losses due to hydro-meteorological disasters. The development of a hydro-meteorological disaster detection model needs a relevant geo-bio-physical parameter. However, by considering the area of Java Island covering $128,297 \mathrm{~km}^{2}$, the parameters should be obtained from remotely sensed data with sufficient spectral, spatial, and temporal resolution. This study used the data from Sea and Land Surface Temperature Radiometer (SLSTR) on board Sentinel-3. SLSTR is the next generation of Alongtrack Scanning Radiometer (ATSR) that gave a reference to the Sea Surface Temperature dataset for other satellite missions (Donlon et al., 2009). The temporal accuracy of SLSTR is $0.1 \mathrm{~K} /$ decade, the 
same as ATSR temporal accuracy (European Space Agency, 2012). Two products of SLSTR that are related to drought detection are Normalized Different Vegetation Index (NDVI) and Land Surface Temperature (LST). The relationship between the current NDVI and the multi-year NDVI has been reported to reflect the degree of drought (Zhou et al., 2020). The example algorithm used in this index is the Vegetation Condition Index (VCI). However, this index cannot be accurate in extreme wetness conditions (Kogan, 1995). To overcome this condition, the Temperature Condition Index (TCI) that depends on Land Surface Temperature (LST) could be implemented in conjunction with VCI. This combination is known as Vegetation Temperature Condition Index (VCTI). Thus, VCTI can monitor the relationship between vegetation temperature and stress due to wet conditions (Kogan 1995). VTCI used a scatter of NDVI and LST to detect the warm edge and hard edge. Then, VCTI was calculated using the single-year warm edge and cold edge (Zhou et al., 2020) to identify drought levels from extreme drought until highly wet in the region.

Thus, this research aims to determine the level of drought in Java Island from Sentinel 3 SLSTR data processing using VCTI. The drought map is then used as a spatial recommendation for reforestation activities to reduce future droughts.

\section{Methodology}

\subsection{Study Area}

The research was conducted in Java Island, located at the coordinates $6^{\circ} 45^{\prime} 35^{\prime \prime} \mathrm{S}-8^{\circ} 43^{\prime} 13^{\prime \prime} \mathrm{S}$ and $105^{\circ} 12^{\prime} 36^{\prime \prime} \mathrm{E}-114^{\circ} 36^{\prime} 19^{\prime \prime} \mathrm{E}$ (Figure 1). The island is bordered by the Indian Ocean (Southern Part), the Sunda Strait (Western Part), the Java Sea (North Part), and the Bali Strait (Eastern Part). On 128,297 $\mathrm{km}^{2}$, over 148 million inhabitants, or 49.8 percent of the Indonesian population, become the world's most populous island (Firman, 2017). Java Island faces serious environmental problems and very rapid developments in the industry, livestock, agriculture, construction, and others in this area.

\subsection{Remote Sensing Data}

The Sentinel-3 satellite is an operational satellite launched by the European Union in 2016. The Sentinel-3 satellite provides data covering the oceans and land with real-time monitoring. Sea and Land Surface Temperature Radiometer (SLSTR) is an instrument of Sentinel-3 developed to take the global scale sea surface temperature (SST) in Kelvin with zero bias and $\pm 0.3 \mathrm{~K}(1 \sigma)$ uncertainty in the $5 \times 5^{\circ}$ latitude-longitude area, with temporal stability of $0.1 \mathrm{~K} /$ decade (European Space Agency, 2012).

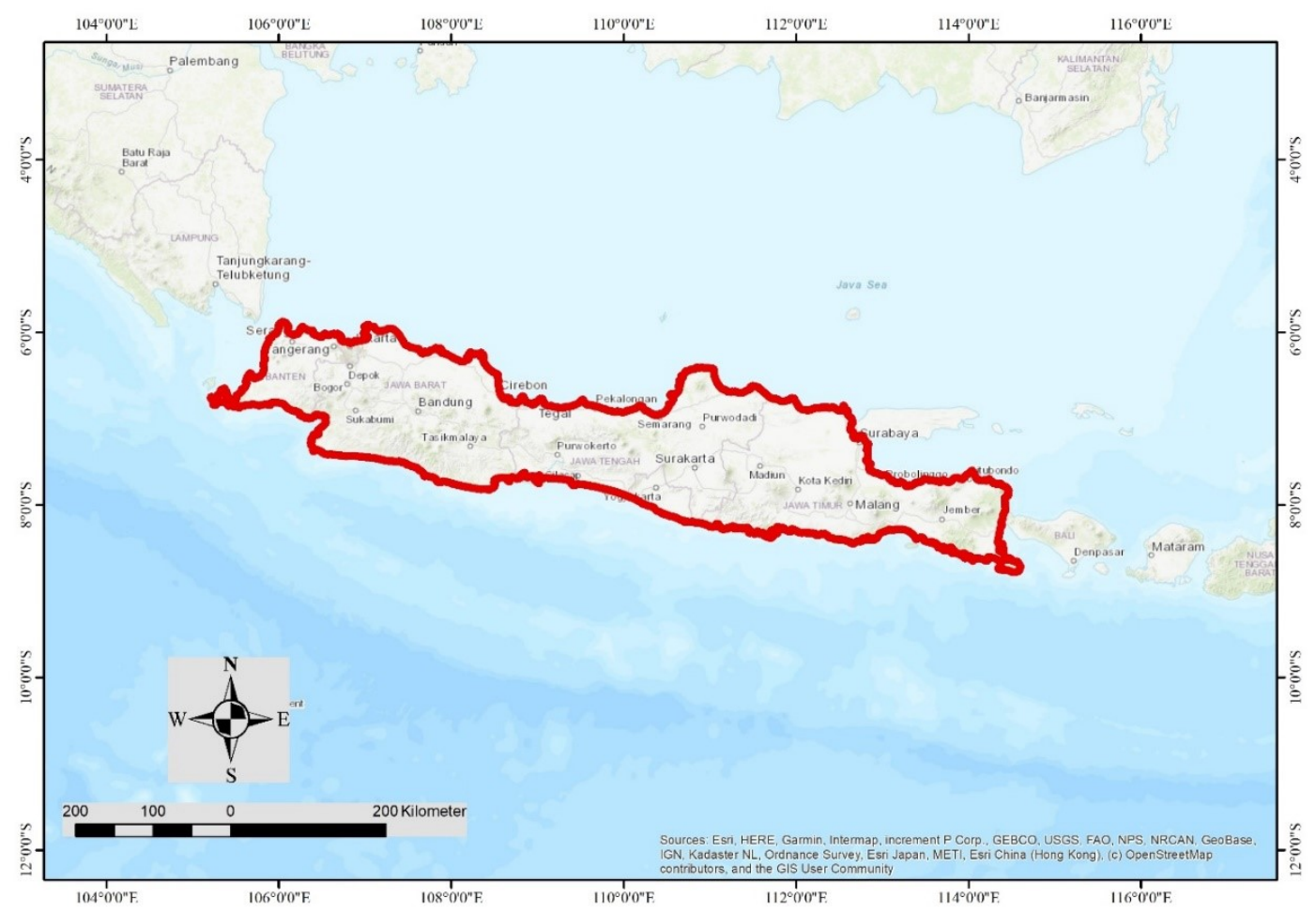

Figure 1: Study area: Java Island, Indonesia 
Table 1: Acquisition date

\begin{tabular}{|c|c|c|c|}
\hline No & Month & \multicolumn{2}{|c|}{ Date } \\
\hline 1 & January & 20180105 & 20180128 \\
\hline 2 & February & 20180201 & 20180228 \\
\hline 3 & March & 20180304 & 20180327 \\
\hline 4 & April & 20180404 & 20180419 \\
\hline 5 & May & 20180608 & 20180620 \\
\hline 6 & June & n/a & n/a \\
\hline 7 & June & 20180701 & 20180717 \\
\hline 8 & July & 20180801 & 20180828 \\
\hline 9 & August & 20180901 & 20180928 \\
\hline 10 & September & 20181006 & 20181029 \\
\hline 11 & October & 20181113 & 20181129 \\
\hline 12 & November & 20181218 & 20181222 \\
\hline
\end{tabular}

The Sentinel-3 SLSTR level-2 LST product has $1000 \mathrm{~m}$ spatial accuracy, and the product can be downloaded from Sentinel Data Hub (https://scihub.copernicus.eu/). Sentinel-3 SLSTR data was used to provide drought monitoring based on scattering between LST and NDVI data. In this study, twenty-two SLSTR Sentinel-3 data were used, recorded two times a month from January to December 2018, except in May (Table 1). The research was conducted every month in 2018 to find out the conditional differences and drought variation during the rainy (June to November) and dry season (December to May). The average rainfall is less than $150 \mathrm{~mm} / \mathrm{month}$ in the dry season and more than 150 $\mathrm{mm} /$ month in the rainy season (BMKG, 2018).

\subsection{Vegetation Temperature Condition Index (VTCI) Method}

The calculation method in this study used the Vegetation Temperature Condition Index (VTCI) algorithm for monitoring drought conditions. VTCI utilizes LST and NDVI space scattering techniques to cancel the extreme wetness condition (Wan and Wang, 2010). The following is the VTCI algorithm:

$$
V T C I=\frac{L S T_{N D V I_{i \max }}-L S T_{N D V I_{i}}}{L S T_{N D V I} i_{\max }-L S T_{N D V I} i_{\min }}
$$

Equation 1

Where, $\mathrm{LST}_{\mathrm{NDVIi} \text { max }}=\mathrm{a}+\mathrm{b} \cdot \mathrm{NDVI}, \mathrm{LST}_{\mathrm{NDVIi} \text { min }}=\mathrm{a}$ '+ b'.NDVI , and $a, b, a$ ', b' are coefficients of linear regression.

In condition, $\mathrm{LST}_{\mathrm{NDVIi}} \max$ is considered as a warm or dry edge when VTCI $=0$. Meanwhile, $\mathrm{LST}_{\mathrm{NDVIi} \text { min }}$ is a cold or wet edge when VTCI $=1$. The VTCI value can indicate the relative degree of dryness. According to (Wang et al., 2004), VTCI is classified into five levels of drought, which are as follows: $0.0<\mathrm{VTCI} \leq 0.2 ; 0.2<\mathrm{VTCI} \leq 0.4 ; 0.4$ $<\mathrm{VTCI} \leq 0.6 ; 0.6<\mathrm{VTCI} \leq 0.8$; and $0.8<\mathrm{VTCI} \leq 1$ for Very Dry; Dry; Balanced Water; Wet and Very Wet, respectively.

\subsection{Processing Flow}

To produce the drought map (Figure 2), some processing steps were conducted. The first step is pre-processing including data sub-setting, reprojection, and filtering to produce NDVI and LST of Java Island. Then, Scatter-space of NDVI and LST were produced to have a relationship between them. In scatter-space there are two liner regressions: at top edge (warm) and bottom edge (cold). The coefficient of two liner regressions: a and $b$ from warm edge; and a' and b' from cold edge. These coefficients were used to produce

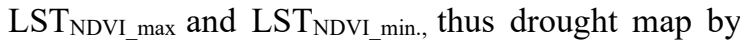
TVCI can be calculated using Equation (1).

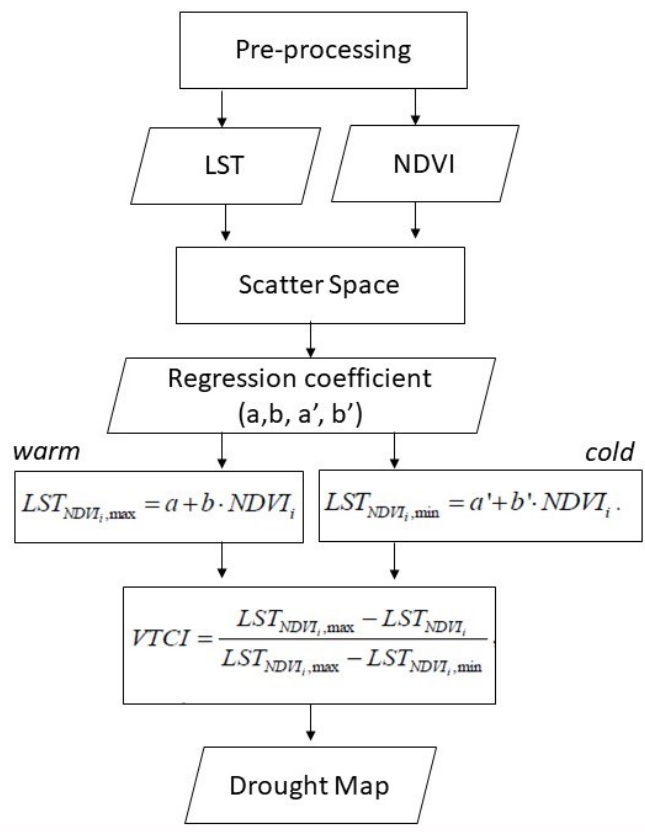

Figure 2: Processing flow 


\section{Result and Discussion}

\subsection{Data Sub-setting and Projection}

Sentinel-3 level-2 SLSTR image data has a global coordinate projection of WGS'84 (EPSG:4326). Furthermore, the data must be projected to follow the location of the research area using the Geographic Latitude/Longitude WGS'84, which is more reliable to the island of Java. The projection step in this study has been carried out using the reprojection tool in SNAP software (https://step.esa.int/main/) (Figure 3).

\subsection{Scatter plot and data extraction}

Sentinel-3 has LST and NDVI data needed to process the data and produce a drought index. A Scatter plot is used to determine the relationship between LST and NDVI variables. Furthermore, the scatter plot between LST and NDVI data is extracted and copied to an excel file that will then be filtered between the LST and NDVI data. Thus, LST and NDVI data have been obtained that match the parameters used (Figure 4). The scatter plot data above shows the relationship between the NDVI parameters in the vertical and LST parameters in horizontal order. The LST data uses kelvin units for this processing.

\subsection{Filtering Data}

The Sentinel-3 level-2 SLSTR is in the form of the Top of Atmosphere (TOA). Therefore, the products from Sentinel-3 are radiometric corrected, calibrated, spectral characterized, and ortho-geolocated. However, Sentinel-3 has not been atmospherically corrected. Thus, Sentinel-3 data is still affected by errors from the atmosphere. Therefore, for LST and NDVI data, filtering is needed to sort out correct and accurate data. The first filtering was carried out on NDVI data. In this processing, the division of 20 intervals was carried out, and then each interval will be further divided into five sub-intervals of NDVI data. This method was to estimate warm and cold edges as was proposed by (Tang et al., 2010) (Figure 5). The process was as follows: first, the LST data interval was filtered by removing the LST data not included in the standard interval range. $L S T a v g \pm 3 \sigma$; the average LST plus-minus three times of standard deviation was used as an indicator. Furthermore, the first filtering results data was used as the initial subinterval filtering data. Second, the subinterval LST data filtering was performed by removing the LST data if the maximum LST value of each subinterval was less than the LSTavg- $\sigma$. Thus, a new maximum LST was obtained for each interval. Furthermore, the warm line's a and b coefficients' values were obtained from the smallest-squares linear regression calculation between the filter results for the maximum LST and NDVI values. The root-meanssquare error (RMSE) values were obtained from the LST regression residues. Thus, the warm edge interval data used for further data processing was the maximum LST data more minor than the LSTavg of the maximum LST plus twice the RMSE. Further, cold edge data is defined in the same way as warm edge data. The temperature on the warm and cold edges obtained in this process was used to process the VTCI algorithm further to produce the Drought Index in Java Island.
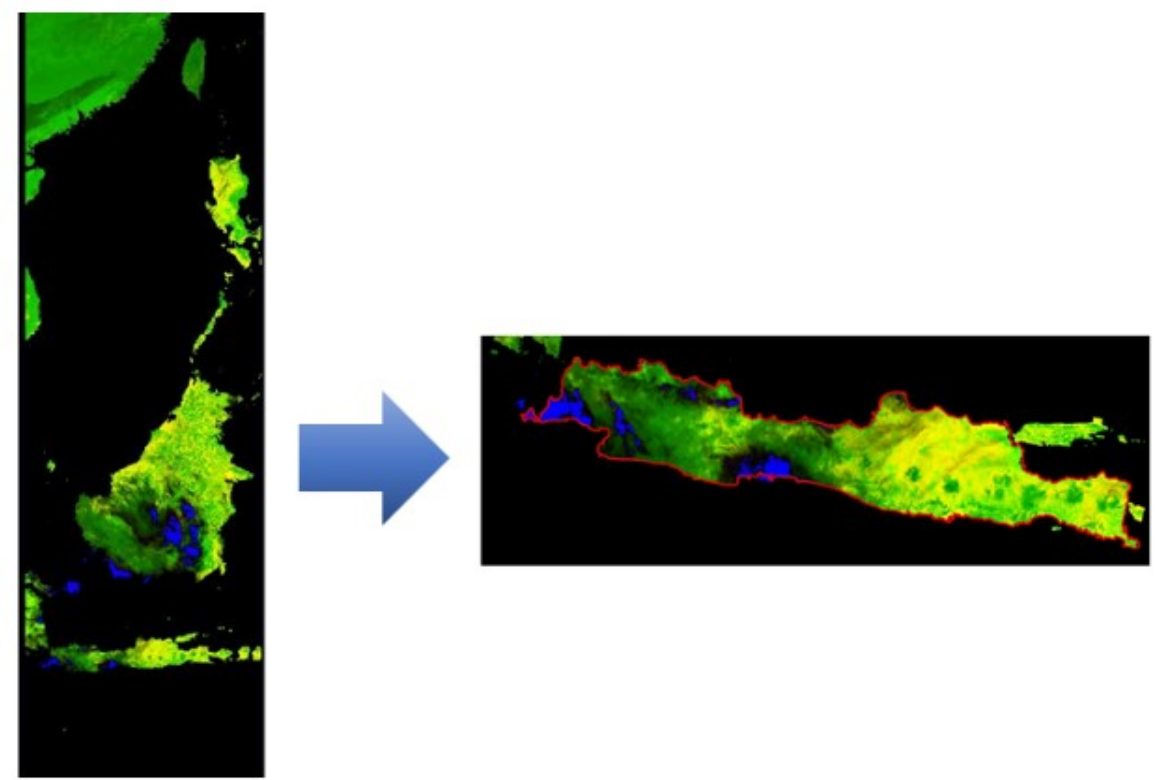

Figure 3: Image projection: before (left) and after (right) 

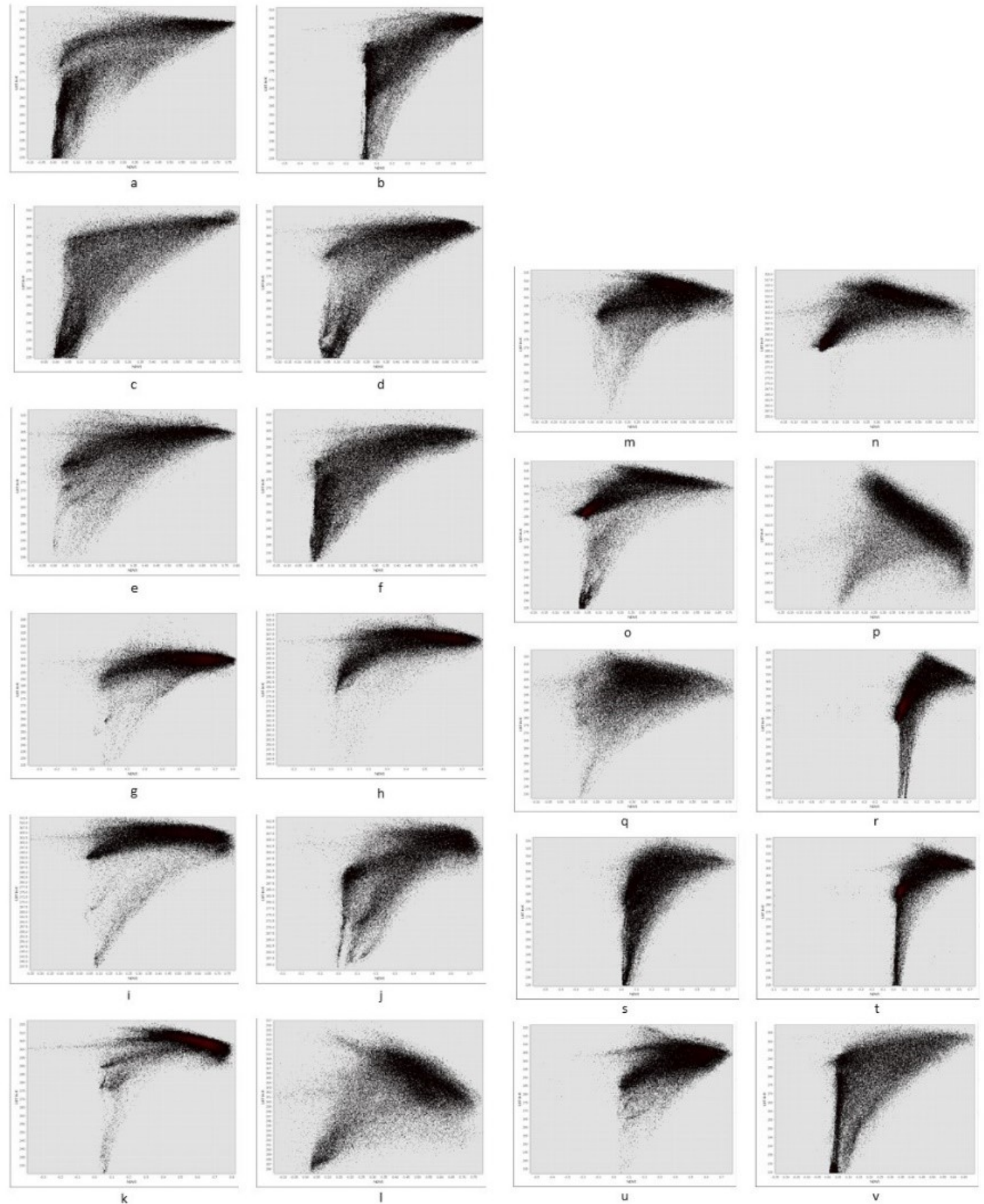

Figure 4: Scatter plot between LST and NDVI Data: (a) January $5^{\text {th }}$, (b) January $28^{\text {th }}$, (c) February $1^{\text {st }},(\mathrm{d})$ February $28^{\text {th }}$, (e) March $4^{\text {th }}$, (f) March $27^{\text {th }}$, (g) April $4^{\text {th }}$, (h) April $19^{\text {th }}$, (I) June $8^{\text {th }}$, (j) June $20^{\text {th }}$, (k) July $1^{\text {st }}$, (l) July $17^{\text {th }},(\mathrm{m})$ August $1^{\text {st }}$, (n) August $28^{\text {th }}$, (o) September $1^{\text {st }}$, (p) September $28^{\text {th }}$, (q) October $6^{\text {th }}$, (r) October $29^{\text {th }},(\mathrm{s})$ November $13^{\text {th }},(\mathrm{t})$ November $29^{\text {th }},(\mathrm{u})$ December $18^{\text {th }},(\mathrm{v})$ December $22^{\text {th }}$ 

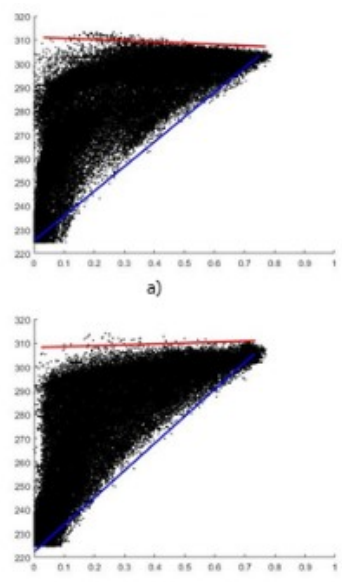

c)

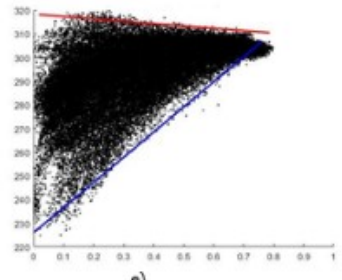

e)
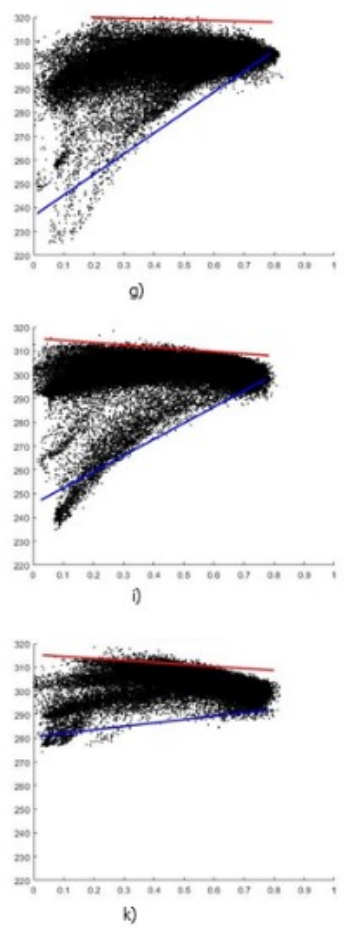

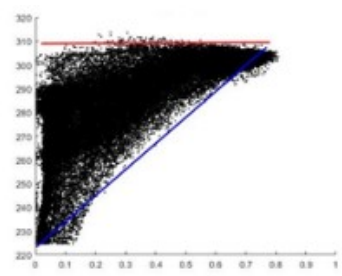

b)
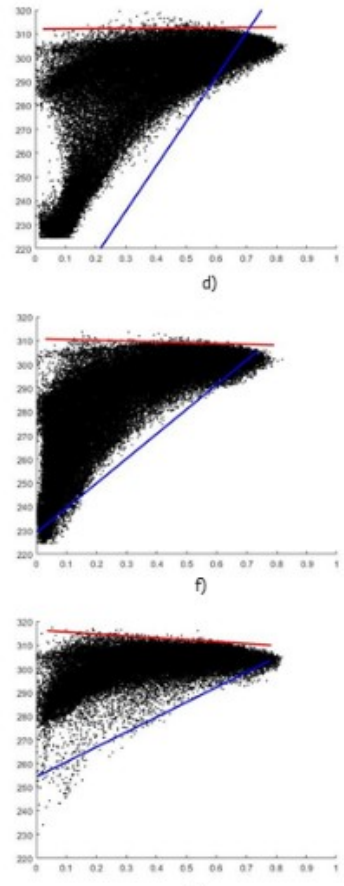

h)
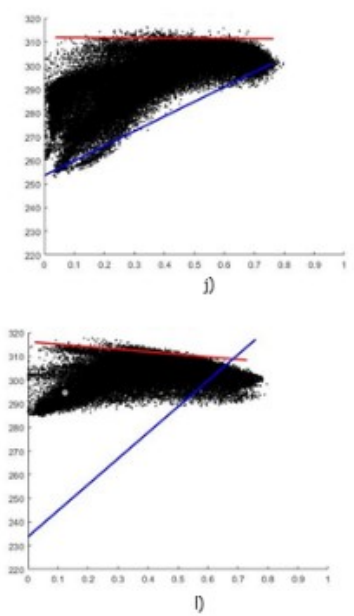
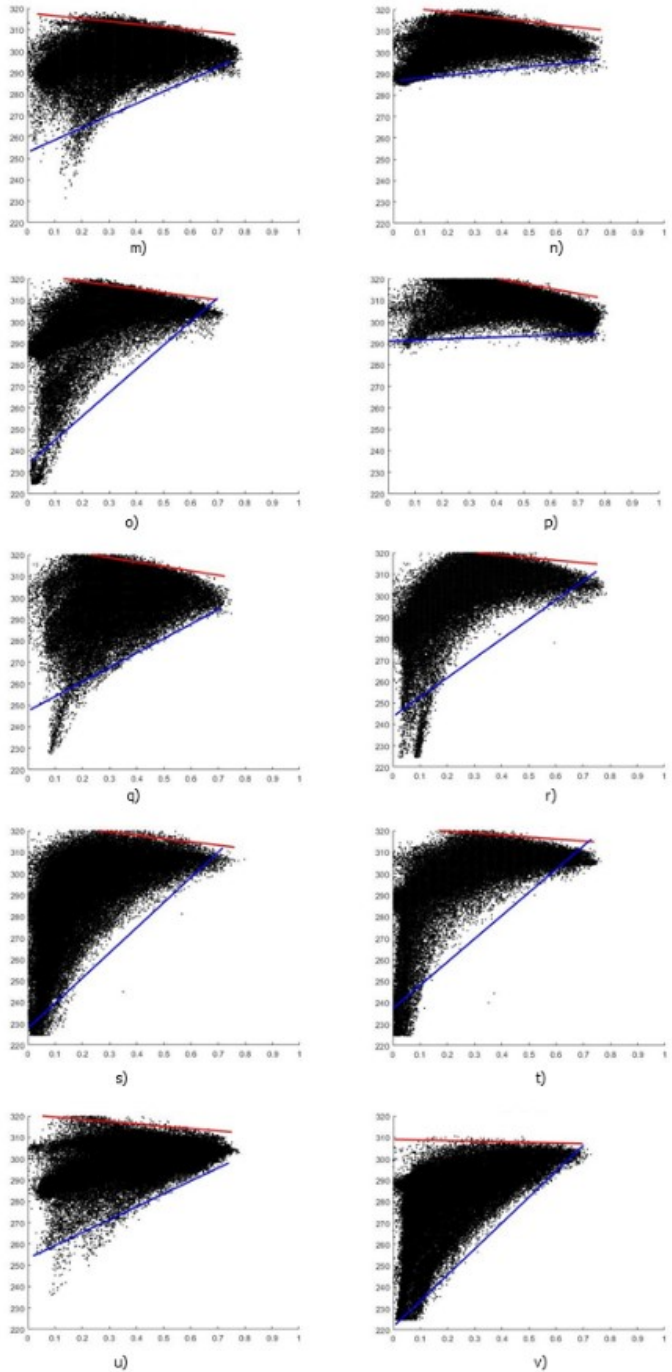

Figure 5: Filtering LST and NDVI data result: (a) - (v) identical with Figure 4

\section{Result and Analysis}

This study uses remote sensing data to monitor the drought condition in Java Island. The data from Sentinel-3 level-2 SLSTR has a spatial resolution of $1 \mathrm{~km}$ to produce LST and NDVI. The LST and NDVI changed every month during 2018. The specific description of the results in this study is as follow.

\subsection{Average Land Surface Temperature (LST) of}

Sentinel-3 SLSTR

The average LST in this study shows the Java Island LST condition each month in 2018. 
Furthermore, the average LST value can show the less and most LST of this study. Besides, the LST condition shows the relationship between LST and drought conditions in this study. Figure 6 shows the average LST value each month from January until December 2018 in Java Island. Furthermore, the graph of the average LST above indicates that the data that has the highest average LST was on September 28, 2018, with the value was $308.872{ }^{\circ} \mathrm{K}$. Whereas, lowest average LST data was on February 1 , 2018, with the value of $277.563{ }^{\circ} \mathrm{K}$. LST reflects thermal waves and the magnitude of their wavelengths.

The LST distribution in Java Island can be seen in Figure 7. In this case, the highest LST was in September 2018, when Indonesia had a dry season. The high value of LST in the dry season causes Java Island to become drier due to low humidity and lack of water due to greater evaporation when the LST value is high. The lowest LST value was found in February 2018 when Indonesia experienced the rainy season. Low LST affects the high humidity in the rainy season. The level of LST also affects the level of existing vegetation. The more greenery, the cooler the temperature is due to the large amount of solar energy absorbed by dark vegetation areas.

Figure 8 show the minimum and maximum LST condition from January to December 2018 in Java Island. The minimum LST condition occurred on February 1, 2018, and the maximum LST condition occurred on September 28, 2018. Furthermore, in Figure 8(a), most Java Island has LST under $300^{\circ} \mathrm{K}$ indicated with orange to blue color on the map. However, in West and Central Java, a high LST of more than $300^{\circ} \mathrm{K}-320^{\circ} \mathrm{K}$ indicated by red color.
Furthermore, the area with the lowest LST that was 220-240 ${ }^{\circ} \mathrm{K}$, occurs in North West Java and easternmost Java shows with blue color. Moreover, for the maximum LST condition (Figure 8b), most Java has LST in the range of $300-320^{\circ} \mathrm{K}$ with red color on the map.

\subsection{Average Normalized Different Vegetation Index (NDVI) of Sentinel-3A SLSTR}

NDVI is an index that shows the level of green leaves or plants health. NDVI ranges between minus one until one; the more significant the NDVI value, the healthier the plant. Many factors affect NDVI, including rainfall, sunlight, humidity, and others. Besides LST, NDVI is also highly given impact of drought. Furthermore, the NDVI value has different each time. In this case, the average NDVI shows the NDVI condition in 2018 (Figure 9). The figure shows the average NDVI on Java Island in 2018. The average NDVI was the highest on July 1, 2018, with the value was 0.466 , and the lowest average NDVI was on November 13, 2018, with the value being 0.221 . The amount of NDVI in Indonesia was influenced by the season that occurs. The NDVI distribution in Java Island can be seen in Figure 10. In this case, the highest NDVI was found in July where the dry season occurs in Indonesia. The high NDVI value can be due to the high density of the available vegetation and its high-water absorption. In the dry season, vegetation requires a sufficient water supply to survive then vegetation water absorption is more increased. The lowest NDVI was found in November where the rainy season occurs in Indonesia. The low NDVI value indicates low water absorption by vegetation.

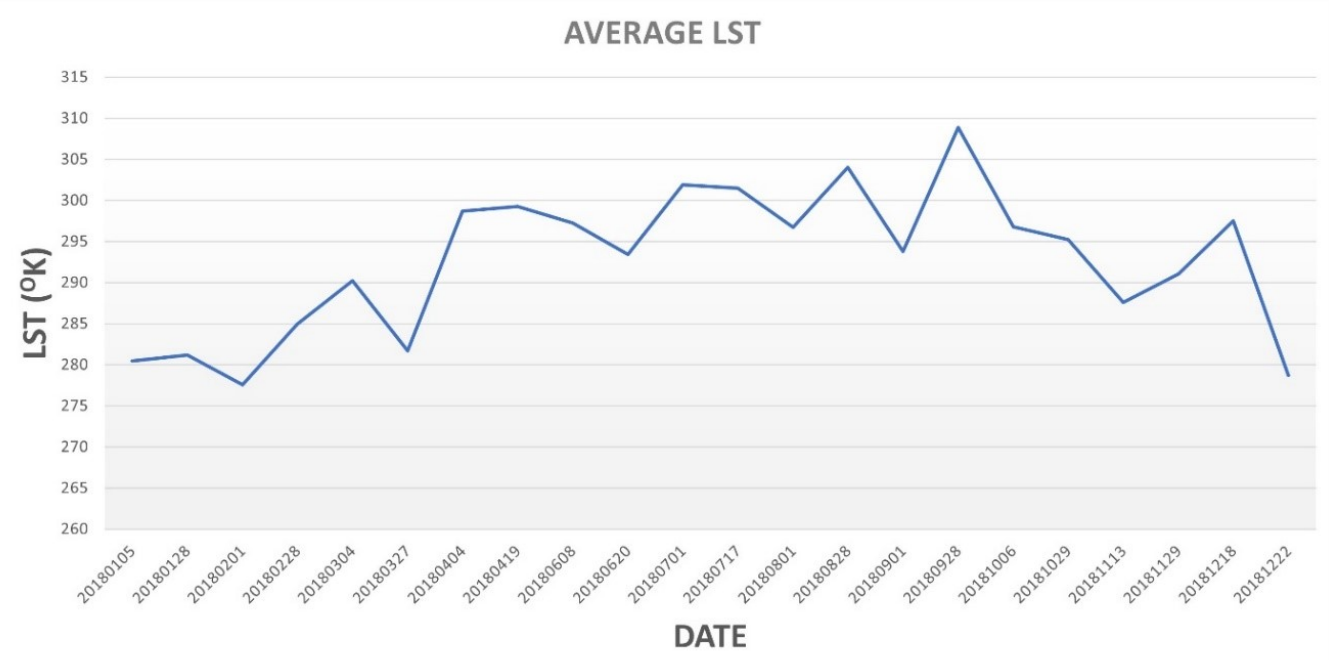

Figure 6: Average LST Sentinel-3 SLSTR in Kelvin $\left({ }^{\circ} \mathrm{K}\right)$ 

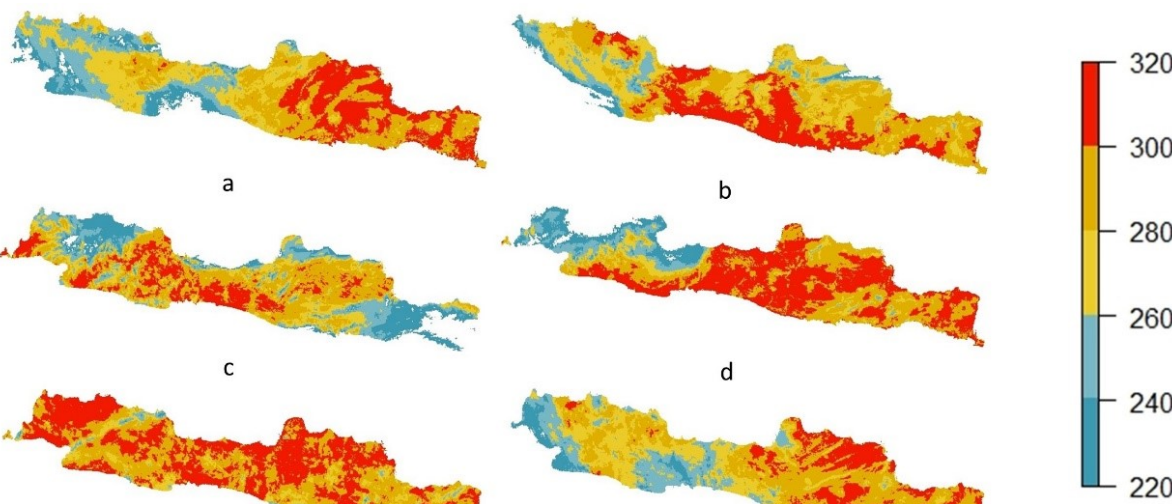

d
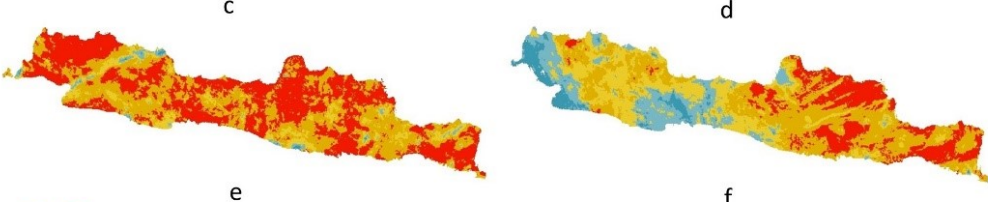

240

220
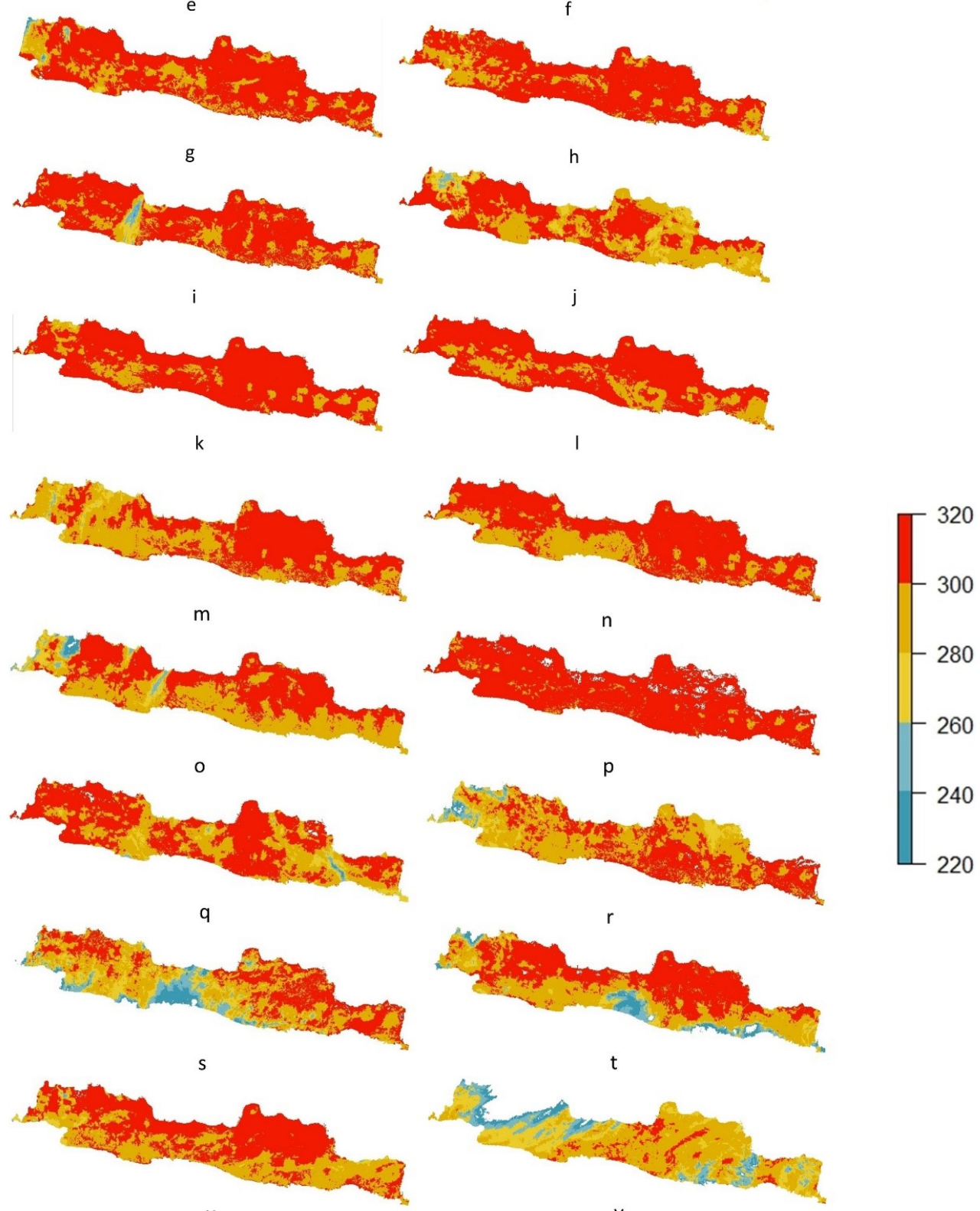

Figure 7: Land Surface Temperature (LST) Maps: (a) - (v) same as Figure 4 


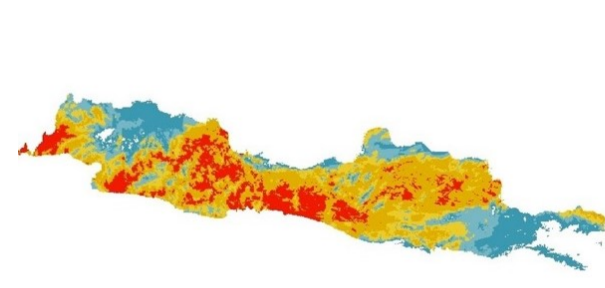

(a)

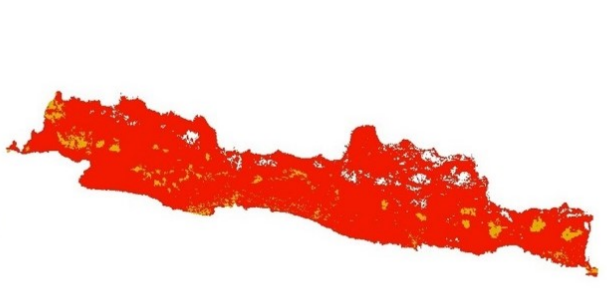

(b)

Figure 8: LST Maps: (a) Minimum LST, (b) Maximum LST AVERAGE NDVI

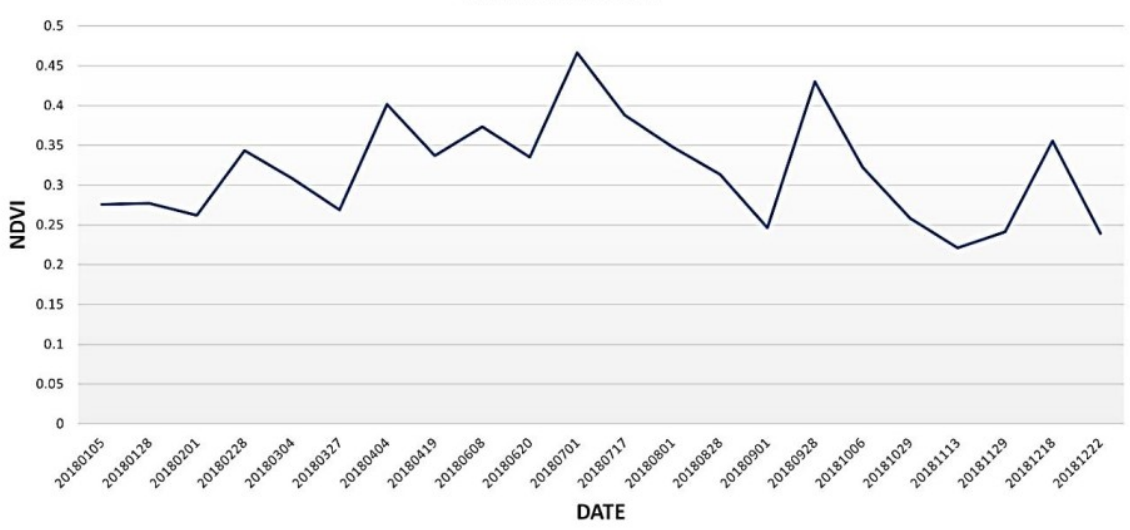

Figure 9: Average NDVI Sentinel-3 SLSTR in 2018

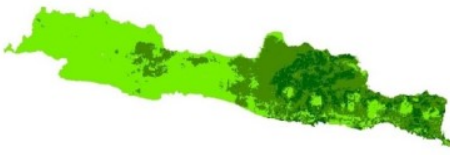

a

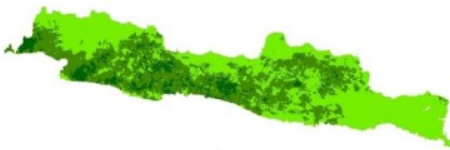

c
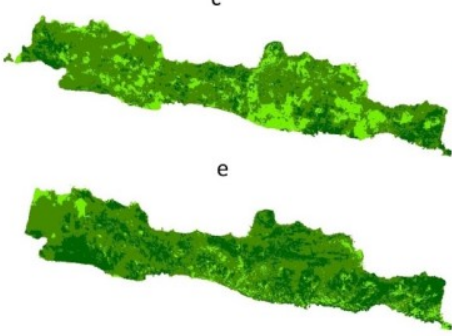

g
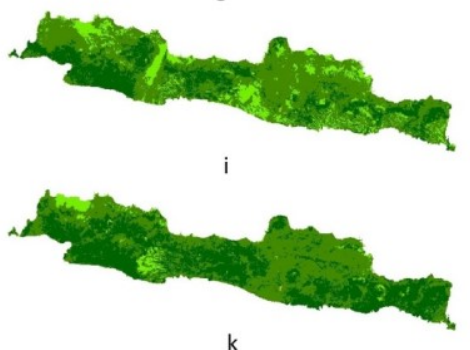

k

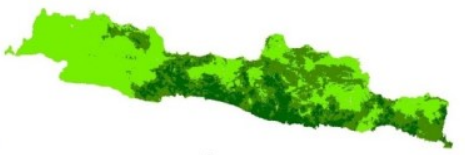

b
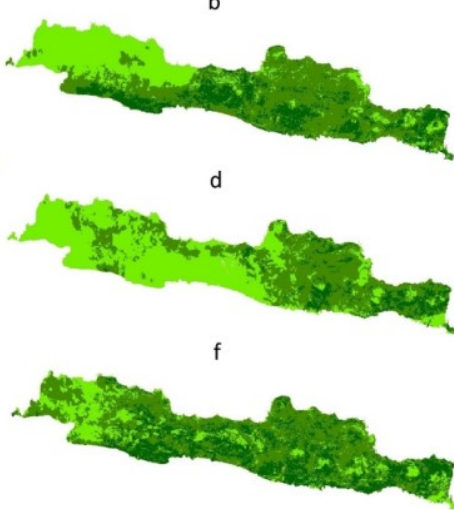

h

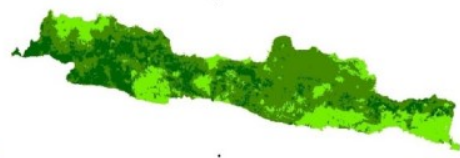

j

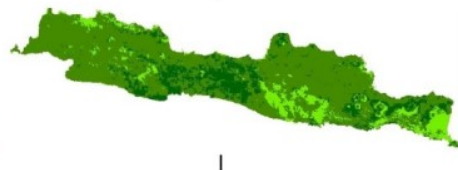

Figure 10: Normalized Different Vegetation Index (NDVI) Maps: (a) - (v) identical with Figure 4 (Continue next page) 

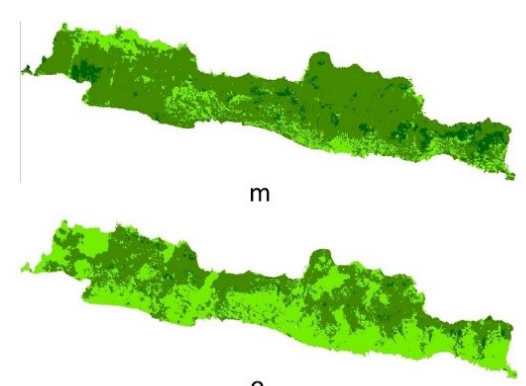

0

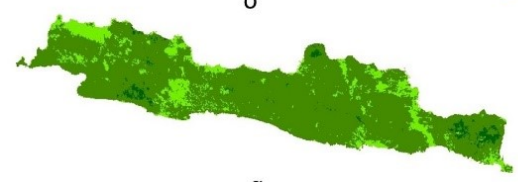

q
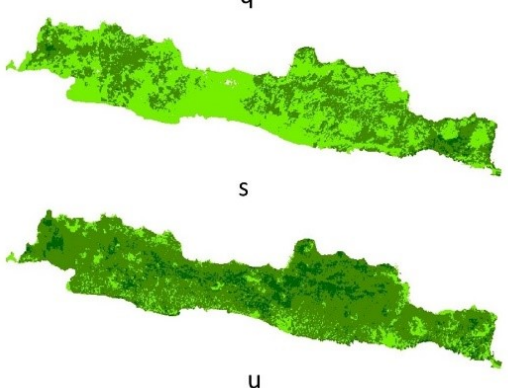
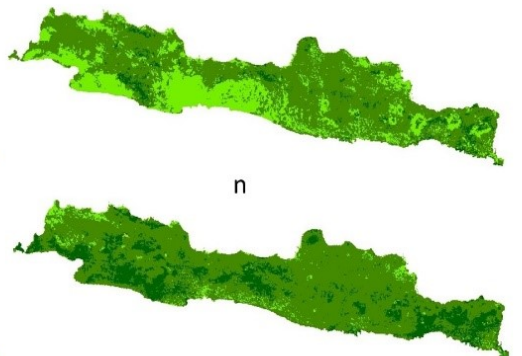

$\mathrm{p}$

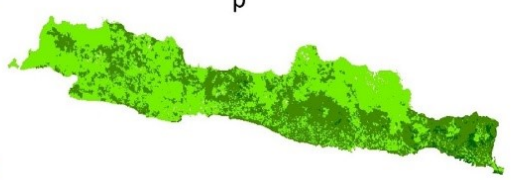

$r$

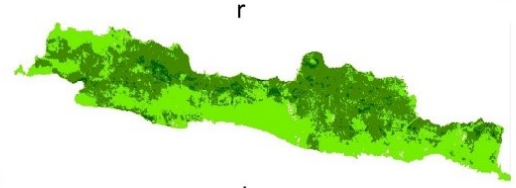

$\mathrm{t}$

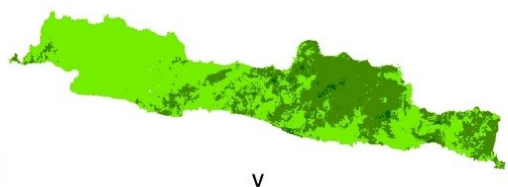

Figure 10: Normalized Different Vegetation Index (NDVI) Maps: (a) - (v) identical with Figure 4 (Continue from previous page)

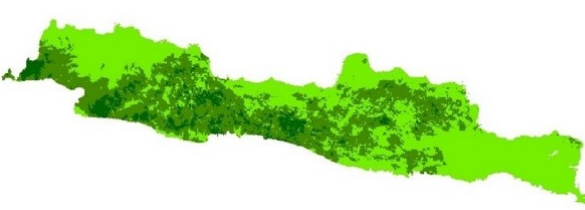

(a)

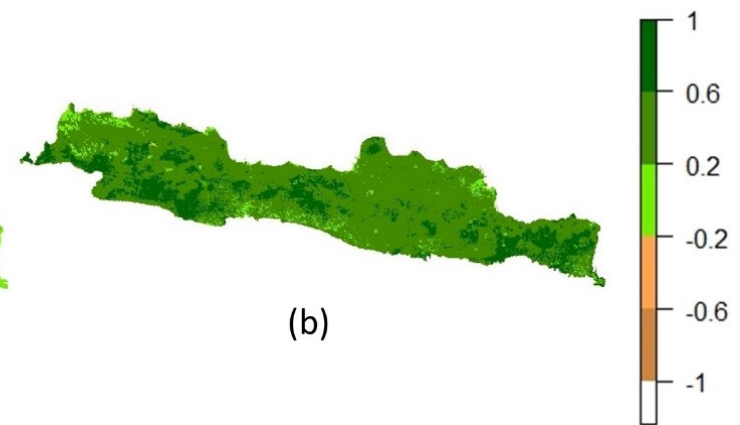

(b)

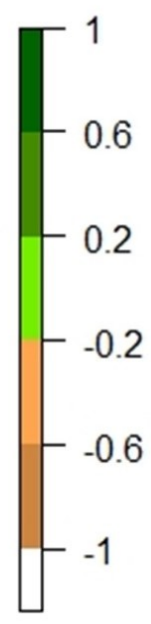

Figure 11: NDVI Maps: (a) Minimum, (b) Maximum

Figure 11 show the minimum and maximum NDVI condition from January to December 2018 in Java Island. The minimum NDVI occurred on February 2, 2018, and the maximum NDVI occurred on September 28, 2018. Furthermore, the NDVI range of this study is from minus one until one. According to Figure 10, the minimum NDVI has an NDVI range value of -0.2 until 0.6 shows light green to green color. Furthermore, several areas in South West and Central Java have higher NDVI values around 0.2 until 1 shows green to dark green color in the map. However, the maximum NDVI has an NDVI range value of 0.2 until 1 shows green to dark green color in a map, but a bit area in West Java has NDVI value -0.2 until 0.2 shows light green color.

\subsection{Vegetation Temperature Condition Index from Sentinel-3A SLSTR}

VTCI is an index that can provide information on the level of drought in an area. The range of VTCI is 0 to 1 . The smaller the VTCI (minimum $=0.0$ ), the drier the area, and the higher the VTCI value (maximum $=1.0$ ), the wetter the area. This study found that VTCI was distributed in Java in 2018, as presented in Figure 12. Java Island experienced the driest condition on July 17, 2018, as shown in Figure 10. Dry conditions were due to having the lowest VTCI value, with an average VTCI value of 0.162 . On July 17,2018 , the LST value and NDVI value were high, with an average LST and NDVI value of $301,472 \mathrm{~K}$ and 0.388 , respectively. 


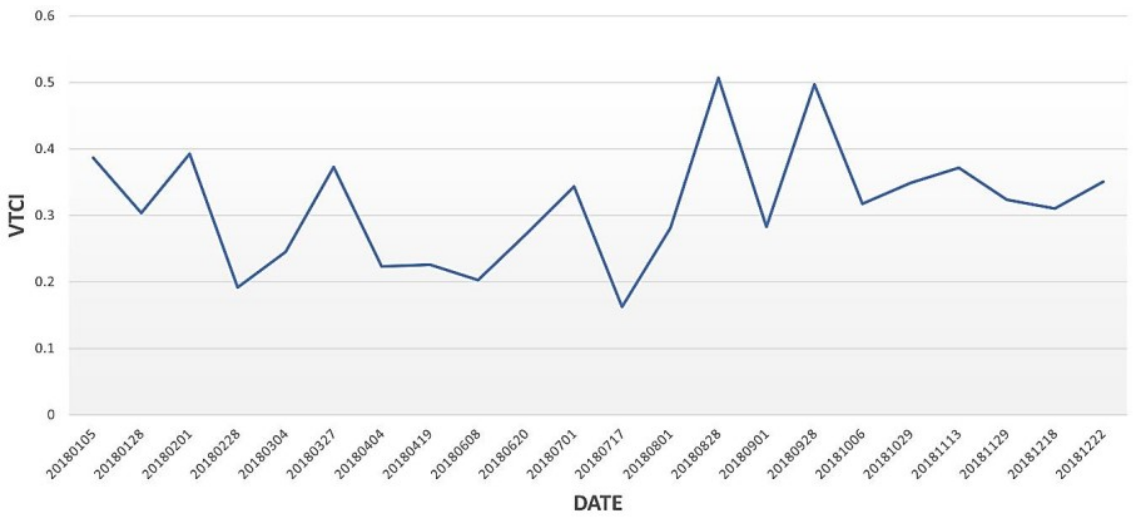

Figure 12: Average VTCI in 2018

The VTCI map has a VTCI interval from 0 (dark red) means very drought, to 1 (dark green) means very wet. On July 17, 2018, the most drought conditions were distributed throughout Java, as seen from the VTCI Map with areas in dark red on Figure 13 (1). Furthermore, August 28, 2018, was the wettest condition throughout 2018. This condition was shown in the VTCI Map Figure 13 with the average wet area spread across the southern part of Java Island, marked by green spaces, and for the northern part of Java Island, the normal condition was almost dry shown in the orange.

\section{Conclusion}

In this study, drought monitoring is carried out over a large area using remote sensing techniques that can be performed quickly and easily. The VTCI algorithm was used to determine the level of drought by considering the relationship between LST and NDVI values to detect hot and cold edge dryness levels. During 2018, the highest and lowest LST occurred on September $28 \quad\left(309^{\circ} \mathrm{K}\right)$ and February $1\left(278{ }^{\circ} \mathrm{K}\right)$. The highest and lowest NDVI occurred on July 1 (0.466) and November 13 (0.221), respectively.

In comparison, the driest conditions indicated the lowest VTCI on July $17(0.162)$ and the wettest on August 28 (0.508). The driest and wettest situation co-occurred: at the end of the dry session and the rainy session, it shows that the rain greatly contributes to high VTCI. We conclude that the detection of drought by LST and NDVI significantly impacts drought monitoring techniques for large areas and on a medium scale. In the future, additional data like solar radiation, land cover, and underground water data, as well as multi-year LST and precipitation, are needed to obtain more accurate drought monitoring results

\section{Reference}

Adede, C., Oboko, R., Wagacha, P. and Atzberger, C., 2019, A Mixed Model Approach to Drought Prediction Using Artificial Neural Networks: Case of an Operational Drought Monitoring Environment. ArXiv, 1-18.

BMKG, 2018, Prakiraan Musim Kemarau 2018 di Indonesia. Jakarta. https://cdn.bmkg.go.id/web/Release_Buku_PMK_2018.pdf.

Donlon, C. J., Casey, K. S., Robinson, I. S., Gentemann, C. L., Reynolds, R.W., Barton, I., Arino, O., Stark, J., Rayner,, N. and LeBorgne, P., 2009, The GODAE High-Resolution Sea Surface Temperature Pilot Project. Oceanography, Vol. 22 (SPL.ISS. 3): 34-45. https://doi.org/10.5670/oceanog.2009.64.

European Space Agency, 2012, Sentinel-3: ESA's Global Land and Ocean Mission for GMES Operational Services. Esa Sp-1322/3.

Firman, T., 2017, The Urbanisation of Java, 2000 2010: Towards 'the Island of Mega-Urban Regions. Asian Population Studies, Vol. 13(1): 50-66.

https://doi.org/10.1080/17441730.2016.1247587.

Kogan, F. N., 1995, Application of Vegetation Index and Brightness Temperature for Drought Detection. Advances in Space Research, Vol. 15(11): 91-100. https://doi.org/10.1016/02731177(95)00079-T.

Murdiyarso, D. and Adiningsih, E. S., 2007, Climate Anomalies, Indonesian Vegetation Fires and Terrestrial Carbon Emissions. Mitigation and Adaptation Strategies for Global Change, Vol. 12(1): 101-12. https://doi.org/10.1007/s11027006-9047-4.

Safitri, S., 2015, El Nino , La Nina Dan Dampaknya Terhadap Kehidupan. Jurnal Criksetra,Vol. 4(8): 153-156. 
Tallaksen, L. M. and van Lanen, H. A. J., (Eds.) 2004, Hydrological Drought - Processes and Estimation Methods for Streamflow and Groundwater. Gulf Professional Publishing.

Tang, R., Li, Z. L. and Tang, B., 2010, An Application of the Ts-VI Triangle Method with Enhanced Edges Determination for Evapotranspiration Estimation from MODIS Data in Arid and Semi-Arid Regions: Implementation and Validation. Remote Sensing of Environment, Vol. 114(3): 540-51. https://doi.org/10.1016/j.rse.2009.10.012.

Van Loon, A. F., 2015, Hydrological Drought Explained. Wiley Interdisciplinary Reviews: Water, Vol. 2(4): 359-92. https://doi.org/$10.1002 /$ wat 2.1085 .
Wan, Z. and Wang, P., 2010, Using MODIS Land Surface Temperature and Normalized Difference Vegetation Index Products for Monitoring Drought in the Southern Great Plains, USA. International Journal of Remote Sensing, Vol. 25(1)37-41. OI:10.1080/0143116031000115328.

Wang, Ch., Qi, S., Niu, Z. and Wang, J., 2004, Evaluating Soil Moisture Status in China Using the Temperature-Vegetation Dryness Index (TVDI). Canadian Journal of Remote Sensing, Vol. 30(5): 671-679. https://doi.org/10.5589/m04-029.

Zhou, X., Wang, P., Tansey, K., Ghent, D., Zhang, S., Li, H. and Wang, L., 2020, Drought Monitoring Using the Sentinel-3-Based Multiyear Vegetation Temperature Condition Index in the Guanzhong Plain, China. IEEE Journal of Selected Topics in Applied Earth Observations and Remote Sensing, Vol. 13, 12942. https://doi.org/10.1109/JSTARS.2019.2953955 . 